\title{
It is possible that tumour-infiltrating granulocytes promote tumour progression
}

\author{
HUANRAN LIU ${ }^{1,3}$, HIDEYUKI UBUKATA ${ }^{1}$, TAKANOBU TABUCHI ${ }^{1}$, AKIRA TAKEMURA ${ }^{1}$, \\ GYOU MOTOHASHI ${ }^{1}$, MOTOI NISHIMURA ${ }^{1}$, TETSURO SATANI ${ }^{1}$, JIANWEI HONG $^{2}$, \\ MOTONOBU KATANO $^{1}$, ICHIRO NAKADA ${ }^{1}$, ABBI R. SANIABADI $^{4}$ and TAKAFUMI TABUCHI ${ }^{1}$ \\ ${ }^{1}$ Fourth Department of Surgery and ${ }^{2}$ Department of Pathology, Kasumigaura Hospital Tokyo Medical University, \\ 3-20-1, Chou, Ami-Machi, Inashiki-Gun, Ibaragi 300-0395, Japan; ${ }^{3}$ Department of General Surgery, \\ First Affiliated Hospital of Dalian Medical University, Dalian 116011, P.R. China; \\ ${ }^{4}$ Japan Immunoresearch Laboratories, Takasaki, Japan
}

Received January 21, 2009; Accepted April 8, 2009

DOI: 10.3892/or_00000402

\begin{abstract}
Several lines of evidence indicate that tumourinfiltrating granulocytes (TIGs) promote tumour growth and progression. However, the prognostic significance of TIGs, the relationship beween TIGs and Fas ligand (FasL) expressed on tumour cells remains unclear and warrants investigation. Using immunnostaining, we retrospectively investigated TIGs and FasL in 130 tissue specimens from gastric carcinoma. We analyzed the correlation among these markers, their association with clinicopathologic features and prognosis. The number of TIGs was significantly associated with FasLexpression $(\mathrm{P}=0.002)$. Further, TIGs were significantly associated with depth of tumour invasion, lymph node metastasis and tumour stage. Calculating the prognostic relevance, in multivariate analysis, TIGs [relative risk $(\mathrm{RR})=1.014 ; 95 \%$ $\mathrm{CI}=1.002-1.027 ; \mathrm{P}=0.015]$ and tumour stage were statistically significant factors for survival. Our results suggest that TIGs are conveniently measured by the immunostaining method, and possibly serve as an independent factor of prognosis in patients with gastric carcinoma. This is based on the fact that TIGs were significantly associated with tumour stage and shorter survival time.
\end{abstract}

\section{Introduction}

In carcinogenesis, cytokines and chemokines from tumour cells can genetically alter epithelial cells and a variety of 'normal' cells, including endothelial cells forming the

Correspondence to: Dr Huanran Liu, Fourth Department of Surgery, Tokyo Medical University, Kasumigaura Hospital, 3-20-1 Chou Ami-Machi, Inashiki-Gun, Ibaragi 300-0395, Japan

E-mail: 1hrlhr9050@yahoo.com

Key words: gastric carcinoma, tumour-infiltrating granulocytes, Fas ligand, prognosis, tumour microenvironment tumour vasculature, fibroblasts and inflammatory cells (lymphocytes, macrophages, mast cells, granulocytes) thus building a supporting microenvironment $(1,2)$. In the microenvironment, cytokines or chemokines from tumour cells can also induc inflammatory cells and contribute to tumour growth, progression and metastasis (3-5). Granulocyte effects on tumour cells represent opposite sides of a double-edged sword (6). In some experimental tumours, granulocytes are cytolytic and can eliminate tumour cell populations (7), whereas in others, granulocytes contribute to the invasive potential $(6,8)$ and induce tumour growth by direct promotion of vessel generation under both physiological (wound healing) and pathological (cancer, psoriasis) conditions (9-13). Therefore, the presence of tumour-infiltrating granulocytes (TIGs) might be indicative for a better or worse host antitumoural response. Recently, we found that the expression of Fas ligand (FasL) on gliomas or melanomas caused an accumulation of neutrophils in tumour sites, and this was associated with a reduction in tumourigenesis and metastasis (14-17).

However, granulocytes, which are important inflammatory cells are believed to be rare in the tumour microenvironment, and the relationship between TIGs and clinicopathologic features, tumour associated antigens (such as FasL) hitherto has received little attention. Therefore, by immunohistochemical methods, we focused on TIGs and their relationship with clinicopathologic features, and the survival of patients with gastric carcinoma.

\section{Materials and methods}

Patient and tumour specimens. We studied patients $(\mathrm{n}=130)$ who underwent gastrectomy between 1999 and 2003. Patients lost to follow-up and patients with synchronous or metachronous multiple cancer were excluded. Adenocarcinoma was confirmed histologically in all patients. Staging of gastric carcinoma was classified according to the 1997 tumour node metastasis (TNM) classification recommended by the International Union Against Cancer (5th edition) (18). None of the patients had received chemotherapy or radiotherapy prior to surgery. Patients classified as stage III and 
IV had received postoperative adjuvant chemotherapy, there was no significant difference in outcome among the patients given various chemotherapeutic agents (data not shown). The patients were 98 men and 32 women, mean age $69.8 \pm 9.4$ years. Overall survival was calculated from the date of diagnosis until the date of death or the last follow-up time. Patients who died due to causes unrelated to carcinoma with no evidence of disease were censored at death.

Detection of TIGs. Immunostaining procedures for TIGs were performed using the Envision+/HRP method (Dako, Carpinteria, CA, USA) with heat-induced antigen retrieval. Two representative blocks of tumour tissue were selected for immunostaining analyses of TIGs. Consecutively, $4 \mu \mathrm{m}$ paraffin sections containing the tumour margin were dewaxed in xylene, then rehydrated in alcohol. For TIG staining, the sections were heated to $95^{\circ} \mathrm{C}$ in an oven for $15 \mathrm{~min}$ to reactivate the antigen, and the endogenous peroxidase activity was suppressed by a solution of $0.3 \%$ hydrogen peroxide in methanol for $30 \mathrm{~min}$. After being rinsed three times in phosphate-buffered saline (PBS), the sections were incubated overnight at $4^{\circ} \mathrm{C}$ with mouse anti-granulocyte (clone SPM250; Spring Bioscience, Fremonet, Germany, 1:50). After washing in PBS, the sections were treated with goat anti-mouse immunoglobulins conjugated to peroxidase labeled-dextran polymer (K4001, Dako) for $40 \mathrm{~min}$ at room temperature. Then the sections were washed in PBS and developed in $0.05 \mathrm{M}$ Tris- $\mathrm{HCl}$ buffer ( $\mathrm{pH} 7.5$ ) containing $0.6 \mathrm{mg} / \mathrm{ml} \mathrm{3,3'-}$ diaminobenzidine tetrahydrochloride (DAB) for $9 \mathrm{~min}$ at room temperature. After washing in water, the nuclei were counterstained with Mayer's hematoxylin. Negative control sections were stained by omitting the primary antibody. To evaluate TIG infiltration, the average number of five representative areas was calculated.

Detection of FasL-expression. FasL-expression in gastric carcinoma was detected by immunohistochemical staining with monoclonal mouse antibody against FasL (5D1; Novocastra Laboratories, Newcastle, UK, 1:50), and treated at $121^{\circ} \mathrm{C}$ in an autoclave for $15 \mathrm{~min}$ for antigen retrieval. Positive control sections were prostates and negative control sections were stained by omitting the primary antibody. We judged specimens to be positive for FasL when at least $20 \%$ of the tumour cells showed positive immunoreactivity.

Statistical analysis. All data including gender, age, stage of disease and pathologic factors were obtained from the clinical and pathology records and included in the univariate and multivariate analyses. Significant differences were determined by Kruskal-Wallis and Mann-Whitney test. Univariate influence of a given parameter on surviaval was assessed with log-rank test, and the Cox proportional hazard regression model was used in multivariate analysis. Any p-value below 0.05 was considered significant.

\section{Results}

The expression of FasL in gastric carcinoma and its correlation with TIGs. The average number of TIGs was 19.5 \pm 15.7 , which were mainly located at the site of the invasion of a tumour (Fig. 1A). The granulocytes in necrotic regions were

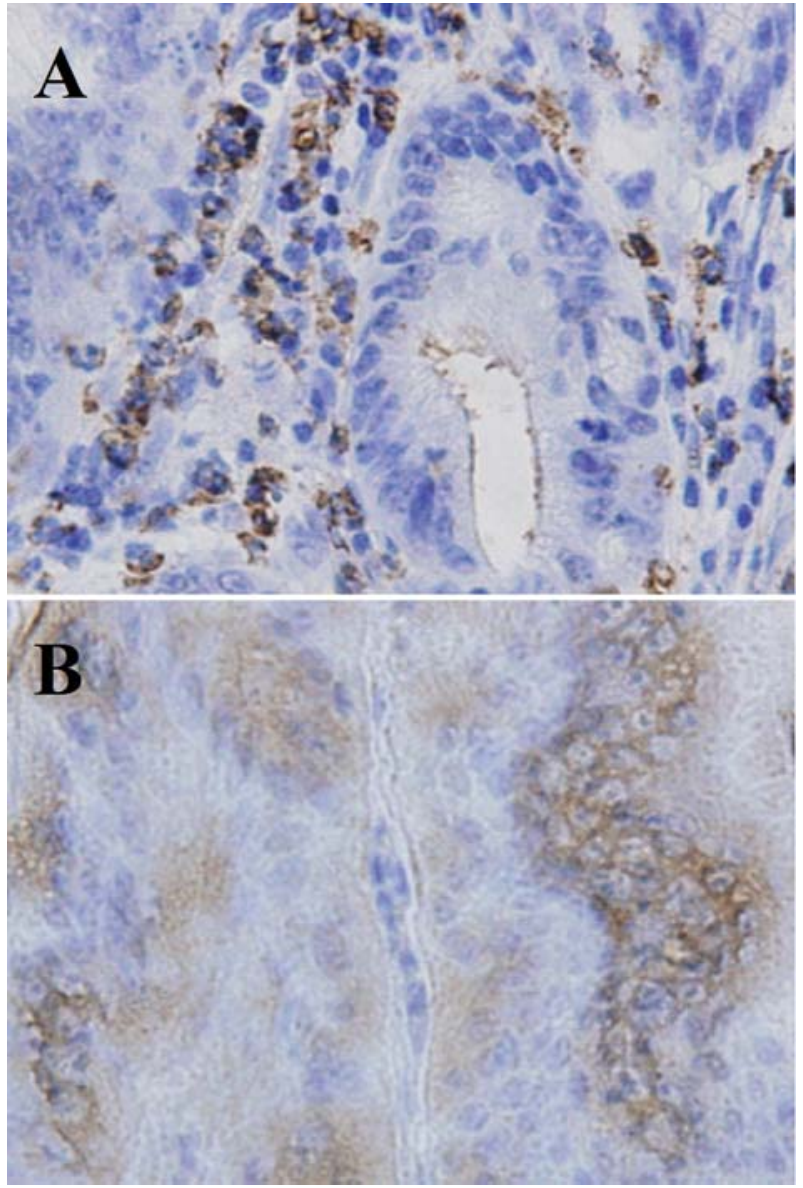

Figure 1. TIG and FasL-expression in gastric carcinoma. (A) and (B) were from the same specimen. (A) TIGs showed a carved tumour tissue. (B) FasL-expression was intense at tumour lesions and was detected both at the cell membrane and in the cytoplasm.

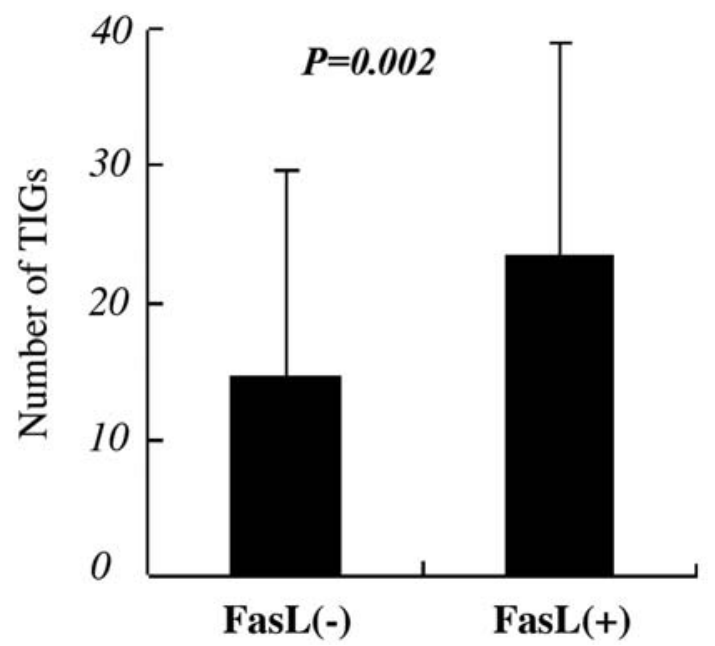

Figure 2. Correlation between FasL-expression in tumour cells and TIGs.

excluded from calculation. FasL-expression by tumour cells was detected in 71/130 (54.6\%). Positive staining of malignant tissue varied in intensity and extent both within individual tumours and between tumours. FasL was located in both cell membrane and in the cytoplasm (Fig. 1B). There was significant correlation between FasL-expression and TIGs ( $\mathrm{P}=0.002$, Fig. 2). 
Table I. TIGs and FasL according to tumour features.

\begin{tabular}{|c|c|c|c|c|c|}
\hline \multirow[b]{2}{*}{ Variable } & \multirow[b]{2}{*}{ TIGs } & \multirow[b]{2}{*}{ P-value } & \multicolumn{2}{|c|}{ FasL } & \multirow[b]{2}{*}{ P-value } \\
\hline & & & - & + & \\
\hline Age & & 0.28 & & & 0.552 \\
\hline$\leq 60$ & $16.05 \pm 15.3$ & & 7 & 11 & \\
\hline$>60$ & $20.1 \pm 15.7$ & & 52 & 60 & \\
\hline Gender & & 0.623 & & & 0.837 \\
\hline Male & $19.0 \pm 15.5$ & & 45 & 53 & \\
\hline Female & $21.2 \pm 16.3$ & & 14 & 18 & \\
\hline Histology & & 0.039 & & & 0.775 \\
\hline Well/moderate & $16.4 \pm 13.5$ & & 38 & 44 & \\
\hline Poor/mucinous & $24.8 . \pm 18.3$ & & 21 & 27 & \\
\hline Depth of invasion & & 0.001 & & & 0.474 \\
\hline Mucosa/submucosa & $10.7 \pm 8.5$ & & 18 & 25 & \\
\hline Musle layer & $20.7 \pm 18.3$ & & 18 & 15 & \\
\hline Subserosa/serosa exposed & $25.9 \pm 16.3$ & & 23 & 31 & \\
\hline Lymph node metastasis & & $<0.001$ & & & 0.268 \\
\hline No & $12.6 \pm 11.0$ & & 29 & 28 & \\
\hline Yes & $25.0 \pm 16.3$ & & 30 & 43 & \\
\hline Stage & & 0.001 & & & 0.654 \\
\hline $\mathrm{I}$ & $511.5 \pm 10.0$ & & 26 & 27 & \\
\hline II & $521.0 \pm 16.5$ & & 9 & 9 & \\
\hline III & $025.1 \pm 16.1$ & & 19 & 28 & \\
\hline IV & $130.4 \pm 17.7$ & & 5 & 7 & \\
\hline
\end{tabular}

TIGs, tumour-infiltrating granulocytes; FasL, Fas ligand.

Table II. Cox regression analysis for survival.

\begin{tabular}{|c|c|c|c|}
\hline \multirow[b]{2}{*}{ Variable } & \multirow{2}{*}{$\frac{\text { Univariate }^{\mathrm{a}}}{\text { P-value }}$} & \multicolumn{2}{|c|}{ Multivariate $^{b}$} \\
\hline & & $\mathrm{RR}(95 \% \mathrm{CI})$ & P-value \\
\hline Age & 0.179 & & NS \\
\hline Gender & 0.388 & & NS \\
\hline Histology & 0.024 & & NS \\
\hline $\begin{array}{l}\text { Depth of } \\
\text { invasion }\end{array}$ & $<0.0001$ & & NS \\
\hline $\begin{array}{l}\text { Lymph node } \\
\text { metastasis }\end{array}$ & $<0.0001$ & & NS \\
\hline TIGs & $<0.0001$ & $1.014(1.002-1.027)$ & 0.015 \\
\hline FasL & 0.221 & & $\mathrm{NS}$ \\
\hline Stage & $<0.0001$ & $1.899(1.578-2.286)$ & $<0.0001$ \\
\hline
\end{tabular}

NS, not significant; RR, relative risk; CI, confidence interval; TIGs, tumour-infiltrating granulocytes; FasL, Fas ligand. ${ }^{a}$ By log-rank test. ${ }^{b} \mathrm{By}$ Cox proportional hazard regression model analysis.
Clinicopathologic factors associated with the TIGs and FasL. Our analysis revealed TIGs to be significantly associated with poor differentiation, deeper tumour invasion, lymph node metastasis and higher tumour stage. FasL-expression was not significantly associated with the clinicopathologic factors. There was also no correlation between the frequency of TIGs with age or gender (Table I).

Analysis of survival. The survival rates of patients with FasLexpression (-, +) were 55.2 and $43.1 \%$ respectively, however, there was no significant difference in the survival rates between these $(P=0.221)$. The number of TIGs was compared in terms of prognostic significance. In univariate survival analysis, the results revealed TIGs, lymph node metastasis, depth of invasion, and tumour stage to be associated with survival. In multivariate survival analysis, number of TIGs $(\mathrm{P}=0.015, \mathrm{RR}=1.014)$ and tumour stage remained statistically significant for survival (Table II). In multivariate analyses for which tumour stage was excluded, lymph node metastasis and depth of invasion were also statistically significant for survival. 


\section{Discussion}

We sought to clarify the presence of granulocytes in the microenvironment of malignant tumours, and to evaluate the relationships between TIGs and FasL clinicopathological manifestations. TIGs have previously been investigated, but results have been unclear because the haematoxylin and eosin staining for detection of TIGs have seriously mislead diagnosis $(19,20)$. The inflammatory microenvironment of tumours is characterized by the presence of host leucocytes, both in the stroma and in the vicinity of tumours (21). TIGs potentially can promote tumour progression via stimulation of angiogenesis and invasion (9-12) or stimulate tumour growth by releasing growth factors (13). Accordingly, in this study TIGs were frequently detected in areas of tumour invasion, and were significantly associated with depth of tumour invasion, lymph node metastasis, poor differentiation and TNM stage. We therefore, believe that TIGs are more likely to contribute to tumour growth, progression and metastasis.

FasL expressed on gastric carcinoma cells can induce tumour infiltrating lymphocyte (TIL) apoptosis, thereby helping tumour cells to evade host immune defense (22-25). Similarly, FasL expressed on gliomas or melanomas promoted an accumulation of granulocytes at tumour sites (14-16), and extensive granulocyte infiltration into tumour tissues are seen in glioma patients (17). Thus, we analyzed their correlation in this study, we detected TIGs and FasL-expression in the same specimens. TIGs showed a significant increase in tumours expressing FasL ( $\mathrm{P}=0.002)$, therefore, we concluded that FasL can induce granulocytes to infiltrate into the tumour, increased TIGs were observed which can antagonize antitumour activities of lymphocytes (26).

In evaluating survival, the number of TIGs was included in Cox regression model, the results revealed that higher number of TIGs $(\mathrm{RR}=1.014)$ and higher tumour stage $(\mathrm{R} R=1.899)$ were significantly associated with poor prognosis.

Further, based on our observations, we have the impression that infiltrating granulocytes promote tumour progression. However, the possibility that granulocytes are not simply a marker of or a result of more advanced disease rather than a cause should be supported by additional investigations. A similar argument might apply to the association of granulocyte infiltration with depth of tumour invasion, poor degree of differentiation, lymph node metastases, and tumour stage. Such investigation should provide a solid basis for granulocyte infiltration as an independent prognostic factor for patients with gastric cancer in clinical settings.

In conclusion, our results suggest that the level of TIGs, which is conveniently measured by the immunostaining method, might serve as an independent predictor of prognosis in patients with gastric carcinoma. This is based on the fact that the TIG level was very significantly associated with tumour stage and shorter survival time. Further, a significant correlation between TIGs and FasL-expression suggests that there are some tumour-associated antigens participating in the infiltration of granulocytes into the tumour.

\section{Acknowledgements}

The authors thank Tsutomu Kohda for technical assistance, Osaka Kazuhisa for statistical assistance and are grateful to Professor J. Patrick Barron of the International Medical Communications Center of Tokyo Medical University for his review of this manuscript.

\section{References}

1. De Visser KE and Coussens LM: The inflammatory tumor microenvironment and its impact on cancer development. Contrib Microbiol 13: 118-137, 2006.

2. Kenny PA and Bissell MJ: Tumor reversion: correction of malignant behavior by microenvironmental cues. Int $\mathrm{J}$ Cancer 107: 688-695, 2003.

3. Burke F, Relf M, Negus R and Balkwill F: A cytokine profile of normal and malignant ovary. Cytokine 8: 578-585, 1996.

4. Koong AC, Denko NC, Hudson KM, et al: Candidate genes for the hypoxic tumor phenotype. Cancer Res 60: 883-887, 2000.

5. Balkwill $\mathrm{F}$ and Mantovani A: Inflammation and cancer: back to Virchow? Lancet 357: 539-545, 2001.

6. Aeed PA, Nakajima M and Welch DR: The role of polymorphonuclear leukocytes (PMN) on the growth and metastatic potential of $13762 \mathrm{NF}$ mammary adenocarcinoma cells. Int $\mathrm{J}$ Cancer 42: 748-759, 1988.

7. Di Carlo E, Forni G, Lollini P, Colombo MP, Modesti A and Musiani P: The intriguing role of polymorphonuclear neutrophils in antitumor reactions. Blood 97: 339-345, 2001.

8. Welch DR, Schissel DJ, Howrey RP and Aeed PA: Tumorelicited polymorphonuclear cells, in contrast to 'normal' circulating polymorphonuclear cells, stimulate invasive and metastatic potentials of rat mammary adenocarcinoma cells. Proc Natl Acad Sci USA 86: 5859-5863, 1989.

9. Cassatella MA: The production of cytokines by polymorphonuclear neutrophils. Immunol Today 16: 21-26, 1995.

10. Bergers G, Brekken R, McMahon G, et al: Matrix metalloproteinase-9 triggers the angiogenic switch during carcinogenesis. Nat Cell Biol 2: 737-744, 2000.

11. Coussens LM, Tinkle CL, Hanahan D and Werb Z: MMP-9 supplied by bone marrow-derived cells contributes to skin carcinogenesis. Cell 103: 481-490, 2000.

12. Benelli R, Albini A and Noonan D: Neutrophils and angiogenesis: potential initiators of the angiogenic cascade. Chem Immunol Allergy 83: 167-181, 2003.

13. Di Carlo E, Forni G and Musiani P: Neutrophil in the antitumoral immune response. Chem Immunol Allergy 83: 182-203, 2003.

14. Chio CC, Wang YS, Chen YL, Lin SJ and Yang BC: Downregulation of Fas-L in glioma cells by ribozyme reduces cell apoptosis, tumor infiltrating cells, and liver damage but accelerates tumor formation in nude mice. Br $\mathrm{J}$ Cancer 85: 1185-1192, 2001.

15. Chen YL, Wang JY, Chen SH and Yang BC: Granulocytes mediate the FasL-associated apoptosis during lung metastasis of melanoma that determines the metastatic behavior. Br J Cancer 87: 359-365, 2002.

16. Hor WS, Huang WL, Lin YS and Yang BC: Cross-talk between tumor cells and neutrophils through the Fas (APO-1, CD95)/ FasL system: human glioma cells enhance cell viability and stimulate cytokine production in neutrophils. J Leukoc Biol 73: 363-368, 2003.

17. Fossati G, Ricevuti G, Edwards SW, Walker C, Dalton A and Rossi ML: Neutrophil infiltration into human gliomas. Acta Neuropathol 98: 349-354, 1999.

18. Sobin LH and Wittekind $\mathrm{CH}$ (eds): TNM Classification of Malignant Tumors. 5th edition. International Union Against Cancer (UICC). New York, Wiley, pp59-62, 1997.

19. Nagashima H, Mori M, Sadanaga N, Mashino K, Yoshikawa Y and Sugimachi K: Expression of Fas ligand in gastric carcinoma relates to lymph node metastasis. Int J Oncol 18: 1157-1162, 2001.

20. Caruso RA, Bellocco R, Pagano M, Bertoli G, Rigoli L and Inferrera $C$ : Prognostic value of intratumoral neutrophils in advanced gastric carcinoma in a high-risk area in northern Italy. Mod Pathol 15: 831-837, 2002. 
21. Negus RP, Stamp GW, Hadley J and Balkwill FR: Quantitative assessment of the leukocyte infiltrate in ovarian cancer and its relationship to the expression of C-C chemokines. Am J Pathol 150: 1723-1734, 1997.

22. Walker PR, Saas P and Dietrich PY: Tumor expression of Fas ligand $(\mathrm{CD} 95 \mathrm{~L})$ and the consequences. Curr Opin Immunol 10: 564-572, 1998.

23. Paul RW, Saas P and Dietrich PY: Role of Fas ligand (CD95L) in immune escape: the tumor cell strikes back. J Immunol 158: 4521-4524, 1997.
24. Strand S, Hofmann WJ, Hug H, et al: Lymphocyte apoptosis induced by CD95 (APO-1/Fas) ligand-expressing tumor cells a mechanism of immune evasion? Nat Med 2: 1361-1366, 1996.

25. Hahne M, Rimoldi D, Schroter M, et al: Melanoma cell expression of Fas (Apo-1/CD95) ligand: implications for tumor immune escape. Science 274: 1363-1366, 1996.

26. Ubukata H, Tabuchi T, Soma T, et al: the role of granulocyte in the immune response network against cancer. Biotherapy 6 : 776-778, 1992. 